\title{
6 OPEN ACCESS \\ Technology support of the handover: promoting observability, flexibility and efficiency
}

Emily S Patterson

Correspondence to Dr Emily Patterson, School of Health and Rehabilitation Sciences, College of Medicine, Ohio State University, 543 Atwell Hall, 453 W 10th Ave Columbus, OH 43210, USA; patterson. 150@osu.edu

\section{ABSTRACT}

Background: Efforts to standardise data elements and increase the comprehensiveness of information included in patient handovers have produced a growing interest in augmenting the verbal exchange of information with written communications conducted through health information technology (HIT).

Objective: The aim of this perspective is to offer recommendations to optimise technology support of handovers, based on a review of the relevant scientific literature.

Recommendations: Review of the literature on human factors and the study of communication produced three recommendations. The first entails making available "shared knowledge" relevant to the handover and subsequent clinical management with intended and unintended recipients. The second is to create a flexible narrative structure (unstructured text fields) for humanhuman communications facilitated by technology. The third recommendation is to avoid reliance on real-time data entry during busy periods. Implementing these recommendations is anticipated to increase the observability (the ability to readily determine current status), flexibility, and efficiency of HIT-supported patient handovers.

Conclusions: Anticipated benefits of technologysupported handovers include reducing reliance on human memory, increasing the efficiency and structure of the verbal exchange, avoiding readbacks of numeric data, and aiding clinical management following the handover. In cases when verbal handovers are delayed, do not occur, or involve members of the health care team without first-hand access to critical information, making 'common ground' observable for all recipients, creating a flexible narrative structure for communication and avoiding reliance on real-time data entry during the busiest times has implications for HIT design and day to day data entry and management operations. Benefits include increased observability, flexibility, and efficiency of HIT-supported patient handovers.

\section{INTRODUCTION}

Efforts to improve patient handovers have resulted in advances in standardising and increasing the comprehensiveness of information included in verbal exchanges, and there have been parallel efforts to augment the verbal handover with written communications conducted through health information technology (HIT). Anticipated benefits of HIT-supported handovers include reducing reliance on human memory, increasing the efficiency and structure of the verbal exchange, avoiding readbacks of numeric data, and aiding work management following the handover. In some cases, technology is desired for its ability to convey information in the event that a verbal interaction is delayed, does not occur or is provided by someone who did not receive all the critical information (eg, on-call personnel, reduced staffing paradigms such as night float, junior trainees). The aim of this article is to provide insights distilled from the literature on human factors engineering and communication.

\section{MAKING ‘COMMON GROUND’ OBSERVABLE}

Efficiency in human-human conversations is often achieved through sophisticated use of 'implicatures', which are defined as meanings that are not explicitly conveyed, but can nevertheless be inferred, on the basis of shared 'common ground' knowledge and understanding between the participants in a conversation. ${ }^{1}$ When using technology to mediate communication, a risk is that communication will be less efficient due to uncertainty about the amount of common ground that can be assumed by the recipient of the written information.

Increasing the 'observability', defined as the ability to easily infer process status, ${ }^{2}$ of the common ground of the intended recipient will aid efficiency. Of particular importance for efficient patient handovers is making clearly observable when the 
recipient: (1) has previously cared for the patient, particularly within the last $24 \mathrm{~h}$ (eg, a 'handback' rather than a handover), (2) has attained a level of medical competence sufficient to understand abbreviated descriptions (eg, 'she is dry'), (3) is a trusted member of a personal network (eg, the care providers have previously negotiated how best to collaborate over time), (4) has sufficient experience working with or in the same unit or discipline to share social norms about how to conduct work (eg, knows when and how to contact specialist care providers for support) and (5) already has knowledge of the patient event that triggered a change in level of care for inter-unit transitions. When there is no or limited common ground among participants in a handover, this may result in erroneous interpretation of information, and this may contribute to errors and adverse events. $^{3}$

In addition to taking advantage of known elements of common ground for intended recipients, it is important to make observable what 'unintended' recipients have access to particular categories of information. One of the main benefits of using HIT to communicate is enabling easy access to previously unavailable information for others who may benefit, such as administrators, quality improvement personnel, legal personnel and patients. While a good deal of common ground may be inferred between senders and the 'intended' recipients of handover information, in many cases, there is less common ground between this group and others who may access the system for a variety of reasons. Therefore, frontline clinicians are typically required to provide additional information to support the information needs of these secondary users. This additional documentation violates 'Grudin's law' for information technology design, which stipulates that a system should avoid requiring users to do work that does not personally benefit them. ${ }^{4}$

This suggests a need to make transparent what information is accessible to unintended recipients for aiding efforts to improve the efficiency of patient handovers. For example, documentation associated with intraunit handovers, such as nursing shift changes, could be made accessible only to clinicians directly providing care to that patient for a 24-h period. This will increase efficiency and reduce the need to make the information understandable to those with less common ground. On the other hand, documentation associated with inter-unit and interorganisational handovers, such as from primary care to the inpatient setting, or from the hospital to a primary care or long-term care setting, is accessible to a wider audience as part of the patient's permanent chart or a shared electronic health record, and requires a more comprehensive approach to data to ensure the information is comprehensible and useful to individuals and groups with less shared common ground.

\section{SUPPORT THE USE OF EVOLVING NARRATIVES TO COMMUNICATE THROUGH TECHNOLOGY}

There are two distinct models for information technology use in the human factors literature. ${ }^{5}$ The first model is to embed automation and decision support in HIT that supports primarily individual cognitive work, which requires interacting with patient data via a computer interface. The second model is to support teamwork through HIT that facilitates communications with other providers who have partially overlapping goals and responsibilities.

Historically, electronic health records have primarily focused on the first model, in particular with respect to supporting billing based on data entered by physicians and nurses. Supporting the first model is often most easily done with structured text fields and associated codes that can easily be aggregated over individual patients in order to generate population-based reports. The second model is likely best supported with a more flexible, narrativebased structure. The narrative structure is arguably the most informative, ${ }^{6}$ easily constructed and remembered, ${ }^{7}$ and empathetic ${ }^{8}$ structure for human-human interaction when coordinating care for an individual patient. Deviations from typical narratives can be easily highlighted (eg, a chronically hypertensive patient being treated for an allergic reaction who also is 16 weeks pregnant). In particular, the status of a situation can be conveyed concisely by employing a Bottom Line Up Front structure, which is typically the first slide in a military briefing. ${ }^{9}$

As more is learned about a patient's history, current trajectory and future trajectory, a narrative can evolve to incorporate new insights without requiring timeintensive and potentially controversial changes to existing information (eg, changing a diagnostic code).

\section{AVOID RELIANCE ON REAL-TIME DATA ENTRY DURING BOTTLENECK OPERATIONS}

A basic concept in systems engineering is that increasing the efficiency and reducing the variation of bottleneck operations is a highly effective approach to reducing non-productive 'wait time' in a system. Some patient handovers are bottleneck operations, such as from the operating room to postoperative care, the emergency department to the inpatient unit, and from the hospital to a long-term care setting or the patient's home. Avoiding or minimising real-time documentation during bottleneck operations will likely increase efficiency.

In addition, technology can be designed to automatically pull information, enter, collect or tag information throughout a shift to be included in handover documentation, and allowing documentation to be completed after a bottleneck period has ended. 
In this article, three recommendations are made. These are: (1) to make common ground observable for both intended and unintended recipients, (2) to allow a flexible narrative structure for human-human communications via the HIT and (3) to avoid reliance on real-time data entry during busy bottleneck time periods. Implementing these recommendations is anticipated to increase the observability, flexibility and efficiency of patient handovers supported by HIT, and their utility for primary and potential additional recipients of the information.

Acknowledgements The research that underlies these recommendations was partially supported by the United States' National Patient Safety Foundation 2011 Hospira Research Award and the Office of Naval Research

(ONR-N000141110222). The views expressed are those of the author and do not necessarily represent the view of the NPSF or ONR.

Competing interests None.

Provenance and peer review Not commissioned; externally peer reviewed.

Open Access This is an Open Access article distributed in accordance with the Creative Commons Attribution Non Commercial (CC BY-NC 3.0) license, which permits others to distribute, remix, adapt, build upon this work noncommercially, and license their derivative works on different terms, provided the original work is properly cited and the use is non-commercial. See: http:// creativecommons.org/licenses/by-nc/3.0/

\section{REFERENCES}

1. Grice HP. Logic and conversation, 1975. Reprinted in: Grice HP, ed. Studies in the way of words. Cambridge, MA: Harvard University Press, 1989, 22-40.

2. Woods DD, Hollnagel E. Joint cognitive systems: patterns in cognitive systems engineering. Boca Raton, FL: Taylor \& Francis Group, 2006.

3. Toccafondi G, Albolino S, Tartaglia R, et al. The collaborative communication model for patient handover: analysis of the interface between high acuity and low acuity care. BMJ Qual Saf. December 2012.

4. Norman DA. Things that make us smart. Reading, MA: Addison Wesley, 1993.

5. Klein G, Woods DD, Bradshaw JM, et al. Ten challenges for making automation a team player in joint human-agent activity. Intell Syst, IEEE 2004;19:91-5.

6. Resnik P, Niv M, Nossal M, et al. Communication of clinically relevant information in electronic health records: a comparison between structured data and unrestricted physician language. Proc Comput Assist Coding 2008, 2008.

7. Poulsen D, Kintsch E, Kintsch E, et al. Children's comprehension and memory for stories. J Exp Child Psych 1979;28:379-403.

8. Charon R. Narrative medicine: a model for empathy, reflection, profession, and trust. JAMA 2001;286:1897-902.

9. Munsey C. Supplying therapy where it is needed most. Monit Psychol 2001;38:42. 